\title{
SUSCEPTIBILITY OF STREPTOCOCCUS AGALACTIAE TO ERYTHROMYCIN AND CLINDAMYCIN IN PREGNANT WOMEN IN THE PRENATAL SCREENING
}

Max Roberto Batista Araújo1, Poliane Vieira dos Reis ${ }^{1}$, Patrícia Helena do Nascimento Bicalho ${ }^{1}$, Luisa Ferreira Seabra ${ }^{1}$

\begin{abstract}
Introduction: Group B streptococcus (GBS), or Streptococcus agalactiae, is a bacterium found in normal human microbiota. However, it may cause neonatal pneumonia, sepsis, and meningitis. Genital colonization in pregnant women is associated with a higher risk of preterm birth. The treatment of choice is antibiotic therapy with beta-lactams, but in the case of multidrug-resistance, erythromycin and clindamycin can be used.

Methods: This study evaluated bacterial cultures in the period from 2014 to 2015 from a group of 29,875 pregnant women. GBS colonization and resistance to erythromycin and clindamycin were investigated.
\end{abstract}

Results: Positive cultures were found in $26.8 \%$ and $26.1 \%$ of the samples in 2014 and 2015 , respectively. Levels of resistance to erythromycin and clindamycin were, respectively, $2.4 \%$ and $5.5 \%$ in 2014 and $3.2 \%$ and $6.5 \%$ in 2015 .

Conclusion: The investigation of GBS colonization and the evaluation of GBS resistance to erythromycin and clindamycin are of extreme relevance, given the increasing incidence of bacterial resistance, risks of preterm birth, and serious consequences to newborns, representing a global health problem.

Keywords: Streptococcus agalactiae; erythromycin; clindamycin; prenatal care; drug resistance, microbial

Group B streptococcus (GBS), or Streptococcus agalactiae, is a Gram-positive, coccoid bacterium with a chain-shaped arrangement, a beta-hemolytic strain, and an invasive potential. It is a nutritionally demanding microorganism that grows well in culture media enriched by the addition of blood, being facultatively anaerobic and homofermentative. Some species multiply faster in an atmosphere rich in carbon dioxide $\left(\mathrm{CO}_{2}\right)$, about 5 to $10 \%{ }^{1}$.

GBS is part of the normal human mucosal microbiota. It is the main cause of neonatal pneumonia, sepsis, and meningitis, as well as the pathogen of serious diseases in adults, contributing to morbidity and mortality in this group of individuals ${ }^{2-4}$.

The normal cervicovaginal microbiota is one of the defense mechanisms against the growth and rise of this pathogenic microorganism. Due to the production of lactic acid, hydrogen peroxide, and other antimicrobial substances, lactobacilli play an important role in the local defense. In pregnancy, imbalance of the vaginal microbiota favors colonization by microorganisms associated with pregnancy complications ${ }^{5}$.

Therefore, $S$. agalactiae infection is an important cause of severe invasive disease in newborns, with sepsis and pneumonia being the most frequent ones. Infections such as meningitis, osteomyelitis, and septic arthritis may also occur. Most of these start early and occur in the first week of life. However, infections may manifest late, up to the third month of life, especially in cases of meningitis. Approximately 15 to $30 \%$ of children who survive S. agalactiae
Clin Biomed Res. 2018;38(4):311-315

1 Núcleo Técnico Operacional, Setor de Microbiologia, Instituto Hermes Pardini. Vespasiano, MG, Brasil.

Corresponding author:

Max Roberto Batista Araújo max_barau@hotmail.com Instituto Hermes Pardini Av. das Nações, 3801 - Parque Jardim Itaú. 33200-000. Vespasiano, MG, Brasil. 
meningitis have neurological sequelae, including blindness, deafness, and severe mental retardation ${ }^{4,6}$.

For this reason, genital colonization of pregnant women with GBS has been associated with an increased risk of preterm birth, and newborns of colonized mothers are at higher risk of contracting infections by this microorganism ${ }^{7}$. There is also a greater risk of systemic dissemination of the microorganism in colonized preterm children as they have immature immune system ${ }^{6,8,9}$. Studies have demonstrated that prophylactic procedures such as intrapartum chemoprophylaxis for pregnant women colonized with $S$. agalactiae presenting with some of the risk factors for child contamination (preterm birth, membrane rupture time greater than or equal to 18 hours, body temperature higher than $38^{\circ} \mathrm{C}$ during labor) may significantly reduce the incidence of vertical infection ${ }^{2,10}$.

The Center for Disease Control (CDC) recommends that bacterial screening is performed routinely in a prenatal examination in pregnant women between 35 and 37 weeks of gestation because colonization is transient. Microbiological screening is recommended through screening of the microorganism in samples of vaginal and rectal secretions from the pregnant woman in order to prevent possible infection of the neonate ${ }^{4,11}$.

Regardless of the clinical form of the neonatal streptococcal disease, chronic neurological sequelae are the major and most costly consequences among survivors. The presence of varied deficits and the continuous need for neurological and physical therapy, among others, make the treatment of sequelae in children onerous to health services and families ${ }^{1}$.

In the 1980s, a significant decrease in neonatal sepsis rates was observed with the use of chemoprophylaxis in pregnant women colonized by GBS. In 1996, in the United States, the CDC published guidelines for the prevention of GBS infection in the prenatal period ${ }^{12}$. In 2002, the CDC updated its pregnancy screening guidelines for detection of GBS colonization between 35 and 37 weeks of gestation, indicating antibiotic prophylaxis in infections during labor ${ }^{13}$. In 2010, a new update on prevention strategies provided new guidelines regarding the rational use of antibiotics, screening, and laboratory methodology ${ }^{14,15}$.

The first choice is beta-lactam antibiotics given that $S$. agalactiae is sensitive to most of these antimicrobial agents, which have the same structure and mechanism of action, i.e., the inhibition of peptidoglycan bacterial cell wall synthesis. The group includes penicillins, cephalosporins, and carbapenems ${ }^{16}$. When the user is allergic to penicillin, erythromycin or clindamycin is chosen ${ }^{15,17}$. Erythromycin belongs to the group of macrolide antibiotics, while clindamycin belongs to the group of lincosamides ${ }^{16}$.

The problem of bacterial resistance to antibiotics is part of the evolution of microorganisms in the struggle for their own survival and consequent maintenance of the species ${ }^{18}$. Thus, indiscriminate use of antibiotics, even in cases of prophylaxis indication, may result in the selection of resistant bacteria, making it an increasing problem.

Considering the increasing number of neonatal infections caused by $S$. agalactiae, the present study evaluated the prevalence of this microorganism in samples from pregnant women collected at or referred to the Hermes Pardini Laboratory, as well as the susceptibility profile to erythromycin and clindamycin.

\section{METHODS}

The results of the survey for $S$. agalactiae from vaginal and perianal samples collected from January to April 2014 and from January to April 2015 were evaluated and compared. The data were collected through electronic records with reports of cultures performed in pregnant patients by the Microbiology department at the Hermes Pardini Laboratory.

Material collection and processing were performed according to the recommendations of the CDC, using a swab for each anatomical site and Stuart transport medium at room temperature. The time elapsed between collection and processing of the material was approximately 48 hours.

In the Microbiology department, the materials were inoculated in Columbia CNA agar (agar base $+5 \%$ sheep blood added with $0.01 \mathrm{~g} / \mathrm{L}$ colistin and $0.015 \mathrm{~g} / \mathrm{L}$ nalidixic acid, bioMérieux ${ }^{\circledR}$, Brazil). The sample was sown on a portion of CNA agar and striated to obtain isolated colonies. The samples were also seeded in thioglycolate broth.

The CNA agar plates were incubated in $5 \% \mathrm{CO}_{2}$ atmosphere at $35 \pm 2{ }^{\circ} \mathrm{C}$ for 48 hours. The thioglycolate broth was incubated in a bacteriological oven at $35^{\circ} \mathrm{C}$ for 24 hours. After the incubation period, the thioglycolate broth was quenched on CNA agar and the plates were incubated for 24 hours at $35 \pm 2{ }^{\circ} \mathrm{C}$ at $5 \% \mathrm{CO}_{2}$.

Plates showing colonies with beta-hemolytic streptococcal characteristics (Figure 1) were considered positive cultures. Plates not showing colonies with these characteristics were considered negative cultures.

Positive cultures were sent for antibiogram and bacterial identification. The antimicrobial susceptibility test was performed on a Muller-Hilton blood plate (Mueller-Hinton agar with $5 \%$ sheep blood, bioMérieux ${ }^{\circledR}$, Brazil), and paper discs impregnated with antibiotics 
were inoculated (Figure 2). Antibiogram results were analyzed after 24 hours of incubation at $35 \pm 2{ }^{\circ} \mathrm{C}$ in the $\mathrm{CO}_{2}$ atmosphere.

For bacterial identification, the SlidexStrepto plus kit (bioMérieux ${ }^{\circledR}$, Brazil) - Rapid agglutination test of latex microparticles was used to classify beta-hemolytic streptococci according to the Lancefield classification.

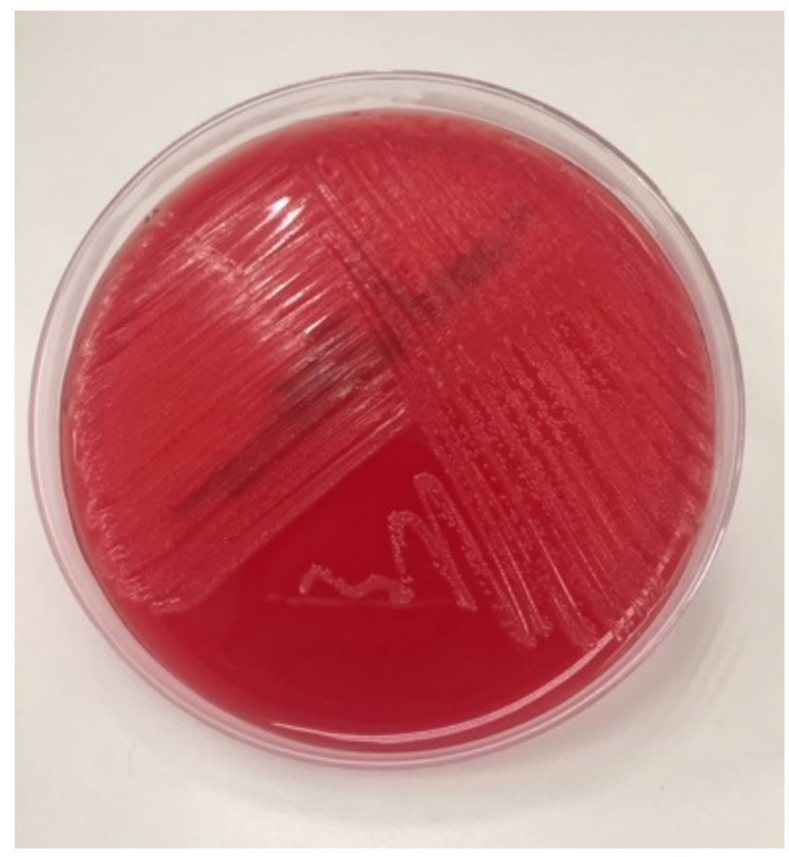

Figure 1: Colonies of $S$. agalactiae on a CNA agar plate.

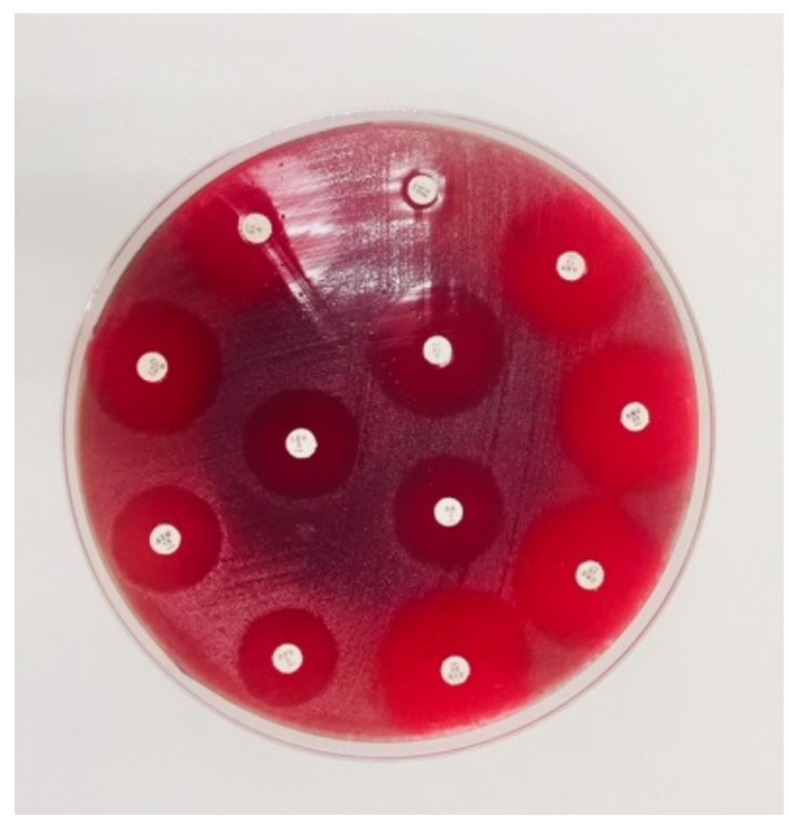

Figure 2: Antimicrobial susceptibility test of $S$. agalactiae on a Mueller-Hinton agar plate with $5 \%$ sheep blood.
Quality control of culture media and antibiotic disks was performed using the Streptococcus pneumoniae strain ATCC 49619 following the recommendations of the Clinical and Laboratory Standards Institute ${ }^{19,20}$.

\section{RESULTS AND DISCUSSION}

The study sample consisted of 29,875 pregnant women who underwent specific GBS screening, 14,442 in 2014 and 15,433 in 2015 . A total of $26.8 \%$ $(3,866)$ and $26.1 \%(4,022)$ positive cultures were found in 2014 and in 2015, respectively (Figure 3). These percentages can be translated into the number of children that could be born colonized with this bacterium and, later on, develop serious and irreversible sequelae.

Prevention is of extreme importance in areas of high incidence of invasive disease by beta-hemolytic GBS. Administering chemoprophylaxis to all pregnant women and newborns is impracticable. The challenge, therefore, is to correctly identify high-risk pregnancies. The most effective way to prevent early-onset neonatal infection is administering antibiotics during labor. However, there is no evidence that chemoprophylaxis prevents late-onset infection ${ }^{14,21,22}$.

The high frequencies found in this study $(26.8 \%$ and $26.1 \%$ ) are in accordance with the literature showing average colonization ranging from 10 to $30 \%$ in different locations ${ }^{23,24}$. Knowledge of local profiles of antimicrobial susceptibility is of great importance because it allows the clinician to provide with more certainty the empirical treatment of chemoprophylaxis when indicated. For intrapartum prophylaxis, penicillin and/or ampicillin are recommended as drugs of choice. Cefazolin is recommended when the pregnant woman is allergic to penicillin and presents a low risk of anaphylaxis. If the risk of anaphylaxis is high, the use of erythromycin or clindamycin is recommended. Vancomycin is an alternative drug for patients allergic to penicillin ${ }^{4}$.

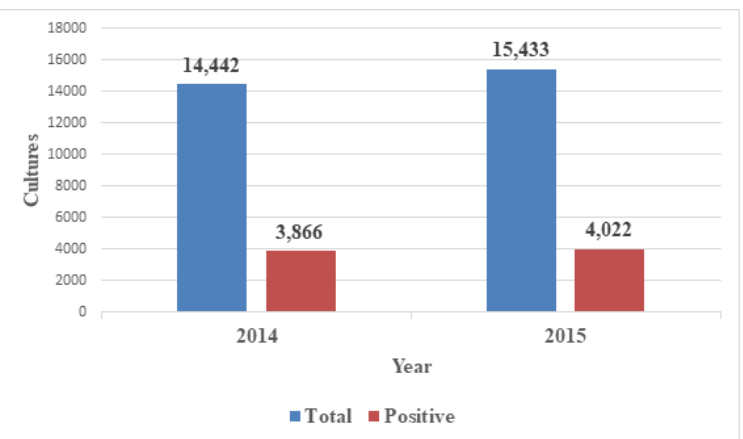

Figure 3: Prevalence of group B streptococcus (GBS). 
In this study, levels of resistance to erythromycin and clindamycin were, respectively, $2.4 \%$ and $5.5 \%$ in 2014 and $3.2 \%$ and $6.5 \%$ in 2015 (Figure 4). Regarding erythromycin, levels of resistance achieved $30 \%$ in the United States, 21.4\% in France, 20\% in Turkey, and $10.7 \%$ in Portugal. These values are higher than those detected in the present study, suggesting a variation of resistance across different populations. Clindamycin showed resistance generally lower than that of erythromycin in other countries, including $17.5 \%$ in France, $11.4 \%$ in the United States, and $9.9 \%$ in Portugal ${ }^{4,23,25}$.

Although the present study demonstrated a lower resistance profile for erythromycin and clindamycin than comparative studies in other countries, there are reports of increased resistance to these antimicrobials ${ }^{16}$, which is of concern, as they may be the choice for

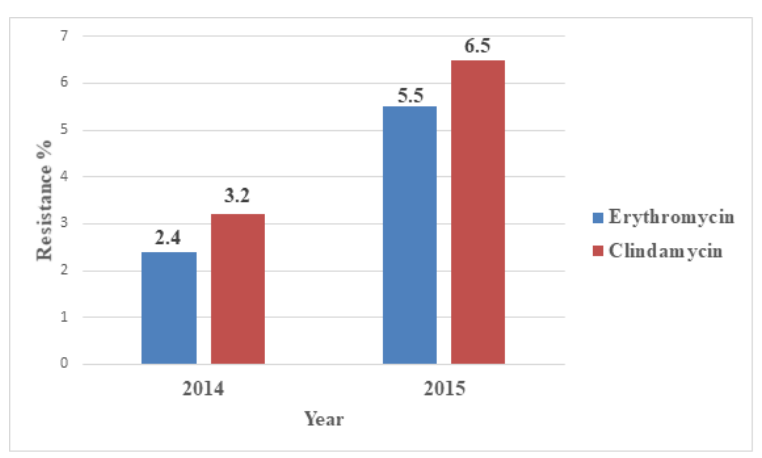

Figure 4: Frequency of resistance of $S$. agalactiae to erythromycin and clindamycin. patients allergic to penicillin. Considering that $S$. agalactiae remains sensitive to penicillin, the use of clindamycin and erythromycin is associated with considerable worries, as resistant strains have been found ranging from 1 to $26 \%^{12}$.

Anaphylactic reactions as adverse effects of antibiotic use are also a cause for concern ${ }^{14,22}$. Therefore, epidemiological studies of $S$. agalactiae colonization should be performed to assess which chemoprophylaxis should be implemented and thus optimize the risk/benefit of this. In Brazil, screening for GBS colonization is not part of the prenatal care protocol proposed by the Ministry of Health ${ }^{26}$. Thus, knowing the incidence of GBS colonization in pregnant women is essential.

\section{CONCLUSION}

$S$. agalactiae is a microorganism whose presence should be investigated and, when found, reported to the clinician in charge. The treatment usually does not present many difficulties, but lack of it may cause serious consequences for newborns.

Erythromycin and clindamycin are antibiotics of particular importance in therapy. As with other drugs, an increase in bacterial resistance to these antibiotics has been found, making it imperative to monitor sensitivity profiles over the years and in each specific population group, as undesirable therapeutic failures may occur, as well as reduction of treatment options.

\section{Conflicts of Interest}

The authors declare no conflicts of interest.

\section{REFERENCES}

1. Caetano MS. Colonização pelo Streptococcus agalactiae (EGB) em gestantes atendidas na Rede Pública de Uberaba-MG [dissertação]. Uberaba: Universidade Federal do Triângulo Mineiro; 2008.

2. Brozanski BS, Jones JG, Krohn MA, Sweet RL. Effect of a screeningbased prevention policy on prevalence of early-onset group B streptococcal sepsis. Obstet Gynecol. 2000;95(4):496-501. PMid:10725479.

3. El Aila NA, Tency I, Claeys G, Saerens B, De Backer E, Temmerman M, et al. Genotyping of Streptococcus agalactiae (group B streptococci) isolated from vaginal and rectal swabs of women at 35-37 weeks of pregnancy. BMC Infect Dis. 2009;9(1):153. http://dx.doi. org/10.1186/1471-2334-9-153. PMid:19747377.

4. Verani JR, McGee L, Schrag SG. Prevention of perinatal group $B$ streptococcal disease. Revised guidelines from CDC. MMWR Recomm Rep. 2010;59(RR-10):1-36. PMid:21088663.

5. Lajos GJ, Passini R Jr, Nomura ML, Amaral E, Pereira BG, Milanez $\mathrm{H}$, et al. Colonização bacteriana do canal cervical em gestantes com trabalho de parto prematuro ou ruptura prematura de membranas. Rev Bras Ginecol Obstet. 2008;30(8):393-9. http:// dx.doi.org/10.1590/S010072032008000800004 .</other>

6. Smith TC, Roehl SA, Pillai P, Li S, Marrs CF, Foxman B. Distribution of novel and previously investigated virulence genes in colonizing and invasive isolates of Streptococcus agalactiae. Epidemiol Infect. 2006;135(6):1046-54. http://dx.doi. org/10.1017/S0950268806007515. PMid:17156495.

7. Adderson EE, Takahashi S, Wang Y, Armstrong J, Miller DV, Bohnsack JF. Subtractive hybridization identifies a novel predicted protein 
mediating epithelial cell invasion by virulent serotype III group B Streptococcus agalactiae. Infect Immun. 2003;71(12):6857-63. http:// dx.doi.org/10.1128/IAI.71.12.68576863.2003. PMid:14638773.

8. Allardice JG, Baskett TF, Seshia MM, Bowman N, Malazdrewicz R. Perinatal group B streptococcal colonization and infection. Am J Obstet Gynecol. 1982;142(6 Pt 1):617-20. http://dx.doi. org/10.1016/S0002-9378(16)32429-2. PMid:7039316.

9. Baele M, Storms V, Haesebrouck F, Devriese LA, Gillis M, Verschraegen $G$, et al. Application and evaluation of the interlaboratory reproducibility of tRNA intergenic length polymorphism analysis (tDNA-PCR) for identification of Streptococcus species. J Clin Microbiol. 2001;39(4):1436-42. http:// dx.doi.org/10.1128/JCM.39.4.14361442.2001. PMid:11283068.

10. Biedenbach DJ, Stephen JM, Jones RN. Antimicrobial susceptibility profile among beta-haemolytic Streptococcus spp. collected in the SENTRY Antimicrobial Surveillance Program--North America, 2001. Diagn Microbiol Infect Dis. 2003;46(4):2914. http://dx.doi.org/10.1016/S07328893(03)00065-8. PMid:12944022.

11. Spellerberg B. Pathogenesis of neonatal Streptococcus agalactiae infections. Microbes Infect. 2000;2(14):1733-42. http://dx.doi. org/10.1016/S1286-4579(00)01328-9. PMid:11137046.

12. Chaves BA. Estudo da colonização por Streptococcus agalactiae, de mulheres em idade fértil, na área metropolitana do Porto [dissertação]. Porto: Faculdade de Farmácia, Universidade do Porto; 2011.

13. Schrag S, Gorwitz R, Fultz-Butts K, Schuchat A. Prevention of perinatal group B streptococcal disease.
Revised Guidelines from CDC. MMWR Recomm Rep. 2002;51(RR11):1-22. PMid:12211284.

14. Verani JR, McGee L, Schrag SJ. Prevention of perinatal group B streptococcal disease. Revised guidelines from CDC. MMWR Morb Mortal Wkly Rep. 2010;59(RR-10):136. PMid:21088663.

15. Borger IL, d'Oliveira REC, Castro ACD, Mondino SSB. Streptococcus agalactiae em gestantes: prevalência da colonização e avaliação da suscetibilidade aos antimicrobianos. Rev Bras Ginecol Obstet. 2005;27(10):575-9. http://dx.doi.org/10.1590/S010072032005001000002.

16. Brunton LL,"Chabner BA,"Knollmann BC. As bases farmacológicas da terapêutica de Goodman \& Gilman. 12. ed. Porto Alegre: Artmed; 2012.

17. Coutinho T, Coutinho CM, Zimmermmann JB, Marcato RM, Coutinho LM. Prevenção da doença perinatal pelo estreptococo do grupo B: atualização baseada em algoritmos. Feminina. 2011 [cited 2018 June 16];39(6):329-33. Available from: URL: http://files.bvs. br/upload/S/0100-7254/2011/v39n6/ a2684.pdf

18. Silva P. Farmacologia. 6. ed. Rio de Janeiro: Guanabara Koogan S.A; 2002.

19. Clinical and Laboratory Standards Institute. Performance standards for antimicrobial susceptibility testing. $24^{\text {th }}$ ed. Wayne, PA: Clinical and Laboratory Standard Institute; 2014. CLSI supplement M100.

20. Clinical and Laboratory Standards Institute. Performance standards for antimicrobial susceptibility testing. $25^{\text {th }}$ ed. Wayne, PA: Clinical and Laboratory Standard Institute; 2015. CLSI supplement M100.

21. El Helali N, Nguyen J-C, Ly A, Giovangrandi Y, Trinquart L. Diagnostic accuracy of a rapid realtime polymerase chain reaction assay for universal intrapartum group B Streptococcus screening. Clin Infect Dis. 2009;49(3):417-23. http://dx.doi. org/10.1086/600303. PMid:19580414.

22. Shet A, Ferrieri P. Neonatal \& maternal group B streptococcal infections: a comprehensive review. Indian J Med Res. 2004;120(3):14150. PMid:15489551.

23. De Azavedo JC, McGavin M, Duncan C, Low DE, McGeer A. Prevalence and mechanisms of macrolide resistance in invasive and noninvasive group B Streptococcus isolates from Ontario, Canada. Antimicrob Agents Chemother. 2001;45(12):35048. http://dx.doi.org/10.1128/ AAC.45.12.3504-3508.2001. PMid:11709331.

24. D'Oliveira RE, Barros RR, Mendonça CR, Teixeira LM, Castro AC. Susceptibility to antimicrobials and mechanisms of erythromycin resistance in clinical isolates of Streptococcus agalactiae from Rio de Janeiro. J Med Microbiol. 2003;52(Pt 11):1029-30. http://dx.doi.org/10.1099/ jmm.0.05278-0. PMid:14532350.

25. Costa ALR, Lamy Filho F, Chein MBC, Brito LMO, Lamy ZC, Andrade KL. Prevalência de colonização por estreptococos do grupo $B$ em gestantes atendidas em maternidade pública da região Nordeste do Brasil. Ver Bras. Ginecol Obstet. 2008;30(6):274-80.

26. Brasil. Ministério da Saúde. Caderno de atenção básica- Atenção ao Pré-Natal de Baixo Risco. Brasilia: Ministério da Saúde; 2012.

Received: Aug 6, 2018 Accepted: Nov 11, 2018 